DOI 10.37882/2223-2982.2020.07.11

\title{
МОДЕЛЬ ПЕДАГОГИЧЕСКОЙ СИСТЕМЫ ФОРМИРОВАНИЯ ПРОФЕССИОНАЛЬНОЙ КОМПЕТЕНТНОСТИ КУРСАНТОВ ВОЕННОГО ВУЗА В УСЛОВИЯХ МОДЕРНИЗАЦИИ ФГОС
}

\section{THE MODEL OF PEDAGOGICAL SYSTEM OF FORMATION OF PROFESSIONAL COMPETENCE OF CADETS OF MILITARY HIGHER SCHOOL IN CONDITIONS OF MODERNIZATION OF THE FSES}

A. Emelyanov

Summary: The article considers the existing models of relations that arise in the learning process and make up the classical organizational model of the pedagogical system. Based on modeling of professional activity was the model of professional training, re-gausa system of formation of professional competence of cadets of military higher school in conditions of modernization of the FSES.

Keywords: competence, cadet, operation of automated control systems, problem, training, model.

\author{
Емельянов Андрей Дмитриевич \\ Филиал ВА РВСН им. Петра Великого в г. Серпухов, \\ emelyanovad@bk.ru
}

Аннотация: В статье рассмотрены существующие модели отношений, возникающих в процессе обучения, и составляющих классическую организационную модель педагогической системы. На основе моделирования профессиональной деятельности была построена модель профессиональной подготовки специалиста, отражающая систему формирования профессиональной компетентности курсантов военного вуза в условиях модернизации ФГОС.

Ключевые слова: компетенция, курсант, эксплуатация АСУ, проблема, обучение, модель.

Особого внимания в составе организационной модели педагогической системы заслуживает модель специалиста, которая служит системообразующим элементом системы. Модель специалиста строится на основе квалификационной характеристики, которая содержит состав знаний, профессиональных компетенций и профессионально значимых качеств личности специалиста.

Модель содержания обучения представляет собой устойчивые отношения между корпусом знаний и способов деятельности, которые могут быть освоены обучающимися в процессе обучения. Обязательным элементом модели является критерии оценки уровня освоения содержания обучения.

Модель управления процессом обучения строится с учетом условий реализации дидактических возможностей принятой технологии и методики обучения:

- особенности методики обучения и дидактических принципов, на ко-торых эта методика основывается;

- соответствие средства и способа представления учебного материала уровню информационной модели курсантов (сложность материала, темп предъявления, стиль учения и др.).

Результатом проектирования и конструирования модели управления про-цессом обучения служит учебно- 


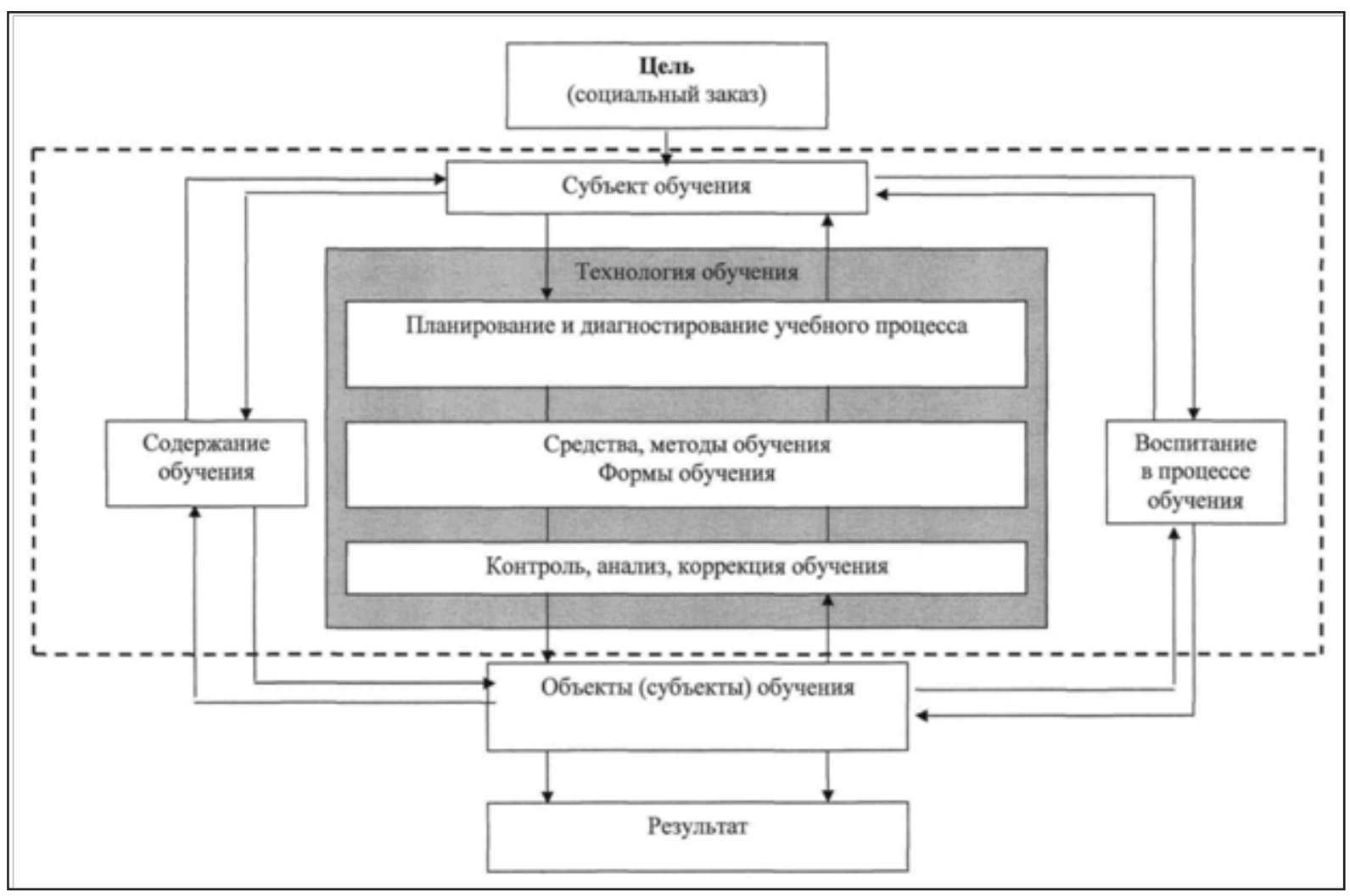

Рис.1. Модель педагогической системы

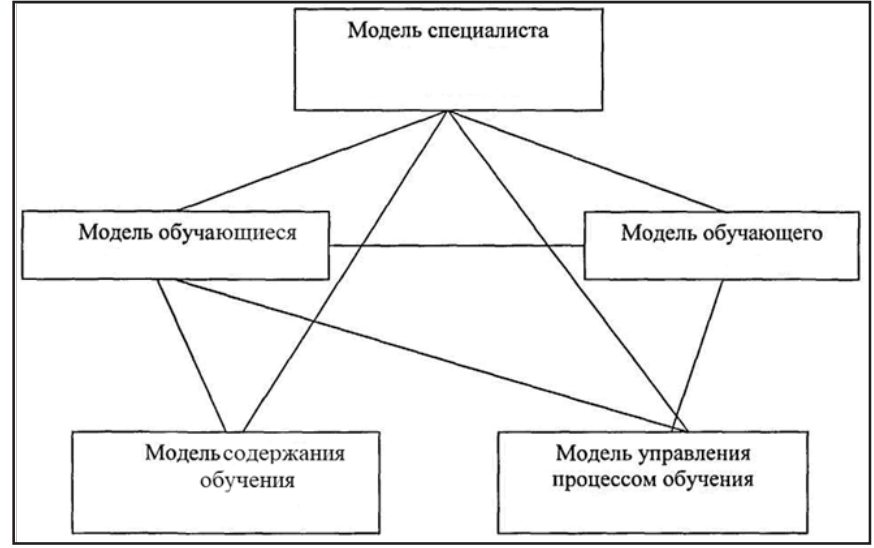

Рис.2. Организационная модель педагогической системы

методическое обеспечение процесса обучения.

Модель обучающегося отражает отношения, возникающие в образовательном процессе, к которым относятся отношения: обучающийся - обучающий, межличностные и межгрупповые отношения обучающихся. Кроме того, модель может содержать отношение обучающегося к содержанию обучения в виде индивидуальных образовательных потребностей и интересов.

Модель содержания образования является предметом педагогической деятельности, в которой под дей-

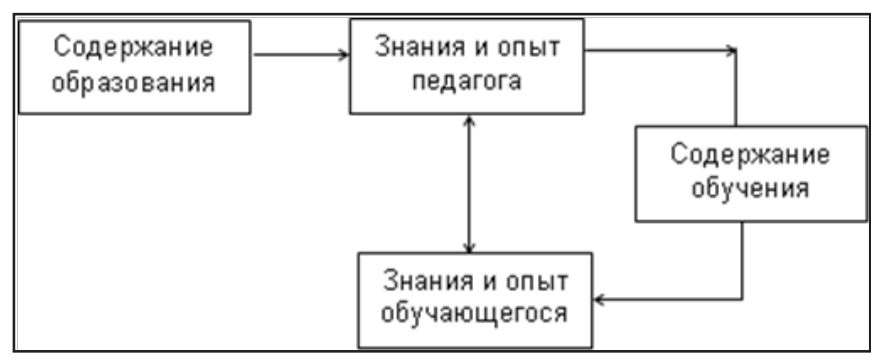

Рис. 3. Модель содержания образования

ствием знаний и опыта педагога рождается содержание обучения (рис.3).

В представленной выше модели учебно-воспитательного процесса, элементами которой являются организационные формы деятельности преподавателя и обучающихся, в качестве системообразующего фактора принимается развитие познавательных способностей обучающихся, стиля их мышления и самостоятельности.

Основой такого развития является система учебных понятий, которые вы-работаны обучающимся в про- 
цессе обучения и которыми он оперирует в своей деятельности. Существует, по крайней мере, два способа построения систем: теоретическая разработка на основе понятий и эмпирическое обобщение наблюдаемых процессов и явлений. При этом, без формирования у обучающихся научных понятий по изучаемому предмету, невозможен переход от воспроизводящей к творческой самостоятельной учебной деятельности.

Как отмечает И.С. Якиманская, если не осуществляется согласование «на-учного» и «учебного» в обучении, оно перестает быть познанием, как отраже-нием объективного мира.

Поэтому в любом виде самостоятельности обучающихся необходимо четко прослеживать два этапа учебной деятельности:

1. этап фиксации понятий;

2. этап их трактовки, понимания, объяснения.

Как сказано выше, для практики обучения имеет большое значение вопрос о критериях оценки уровня освоения обучающимися содержания обучения. Наличие системы критериев и показателей уровней усвоения позволяет оценить качество процесса обучения. При этом содержание обучения должно рассматриваться в аспекте соотнесения представленной системы знаний и избираемой методики организации самостоятельной деятельности обучающегося с уровнями самой его познавательной деятельности.

Уровни сформированности знаний, выделенные Н.А.Менчинской, являются универсальными и соответствующими целям исследования [2] (табл 1).

Таблица 1

\begin{tabular}{|l|l|}
\multicolumn{3}{|c|}{ Уровни сформированности знаний } \\
\hline Уровни & Критерий \\
\hline Первый & $\begin{array}{l}\text { обучающийся может отличить один предмет от друго- } \\
\text { го, но отдельные признаки их указать не может }\end{array}$ \\
\hline Второй & $\begin{array}{l}\text { обучающийся может указать признаки понятий, но не } \\
\text { может отделить существенные признаки от несуще- } \\
\text { ственных }\end{array}$ \\
\hline Третий & $\begin{array}{l}\text { обучающийся усваивает все существенные признаки, } \\
\text { но понятие оказывается еще скованным единичными } \\
\text { образами, служившими опорой при формировании } \\
\text { понятия }\end{array}$ \\
\hline Четвертый & $\begin{array}{l}\text { обучающийся свободно оперирует понятием в реше- } \\
\text { нии различного рода задач }\end{array}$ \\
\hline
\end{tabular}

А.В. Усова добавляет к перечисленным выше уровням пятый, который ха-рактеризуется установлением межпредметных связей, высоким уровнем систематизации и обобщения знаний об объектах, отражаемых в сознании посредством понятия и методов поэлементного и пооперационного анализа для проверки количественной оценки качества усвоения понятий [3].

Примером структурной модели учебной деятельности является модель обучения, которая основана на классической теории поэтапного формирования умственных действий П.Я. Гальперина [4].

Соответствующее дидактическое положение утверждает, что при получении информации обучающийся воспринимает и усваивает одни виды информации в большей степени, чем другие. При этом «в процессе усвоения и использования этой информации, обучающийся оценивает ее по-разному» [5].

Согласно модели учебной деятельности, по отношению к информации обучающиеся отличаются друг от друга по двум характеристикам.

1. Способу сбора информации.

2. Способу оценки и использования информации (рис.4).

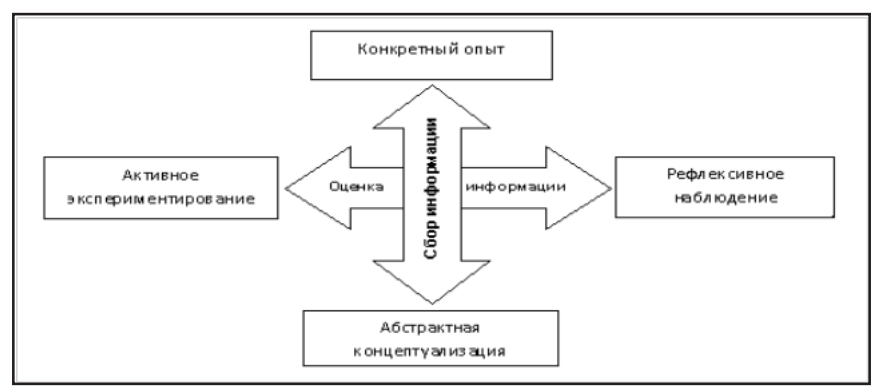

Рис.4. Процесс обработки информации обучающимся

Самые существенные связи и отношения, которые характеризуют процесс обучения - это отношения между обучающим и обучающимися, представлены в модели обобщенно в виде организационных отношений (рис.5).

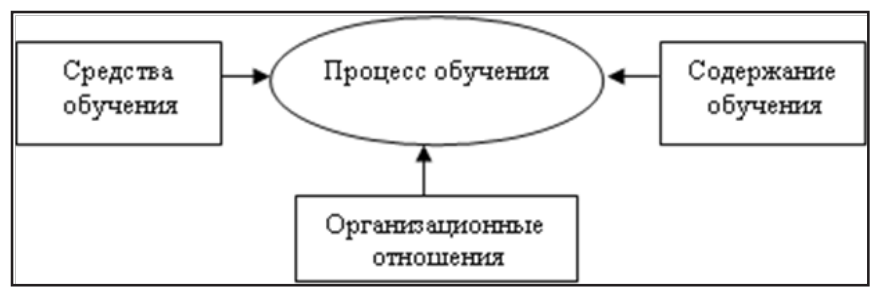

Рис.5. Модель процесса обучения

Педагогическая модель деятельности создается для системного представления деятельности обучающего и обучающихся (преподавание и учение), как через общий предмет их деятельности - содержание обучения, так и отношения, возникающие между ними в процессе обучения. При разработке модели деятельности используются анализ реальной профессиональной деятельности 


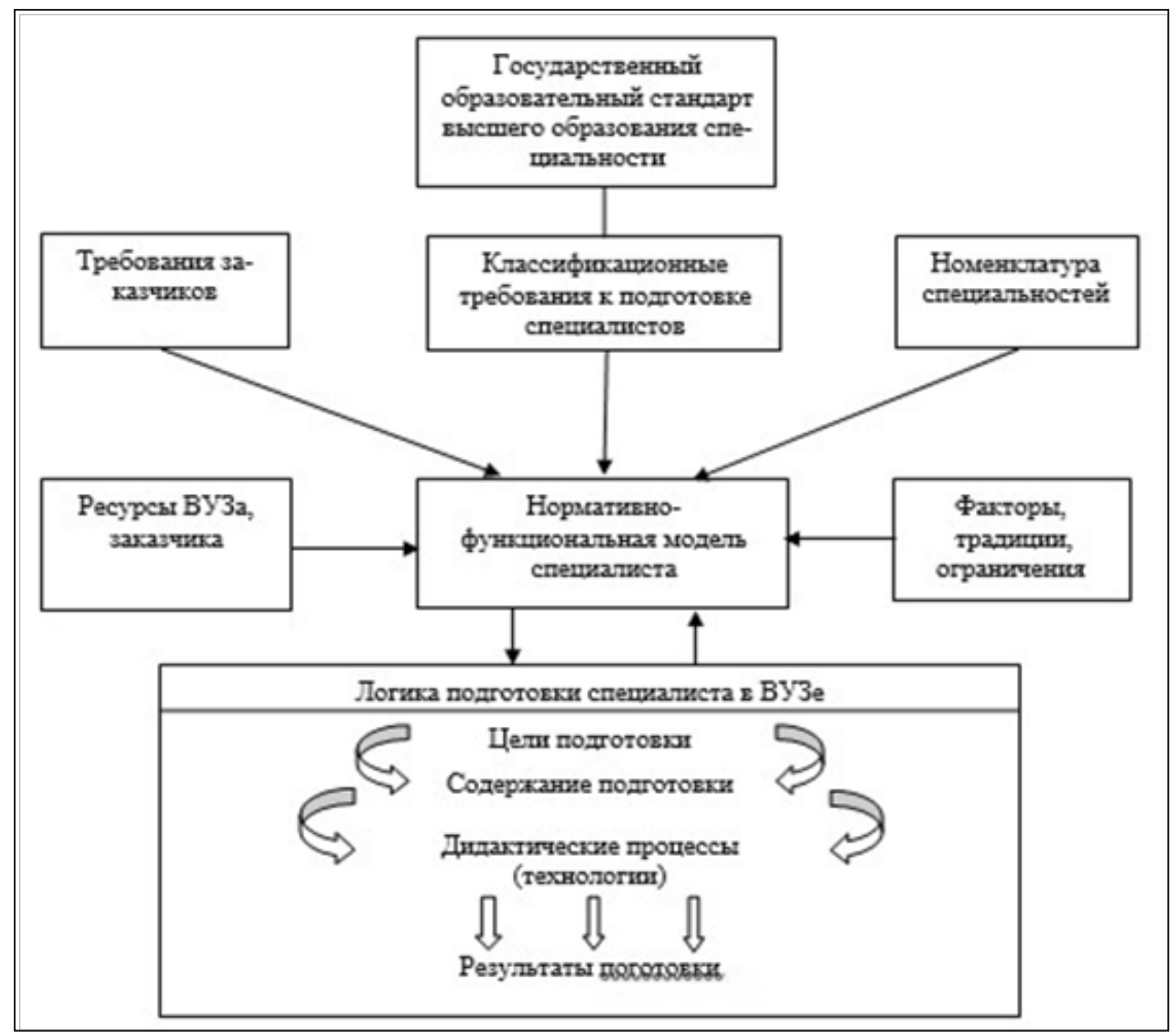

Рис.6. Модель профессиональной подготовки специалиста

и прогноз ее развития в соответствии с научно-техническим прогрессом и др.

Таким образом, модель педагогической системы формирования профессиональной компетентности курсантов военного вуза должна отражать существенные свойства процессов, происходящих в системе. Содержательной основой модели педагогической системы являются представления субъекта исследования, который с ее помощью определяет характер и количество связей, определяющих поведение объекта моделирования.

В педагогических исследованиях используются разного вида модели, слу-жащие средством изучения закономерностей педагогических явлений и процес-сов. Каждая педагогическая модель строится на основе определенных теоретических положений и раскрывает сущность спроектированной педагогической системы.
Подобные модели широко используются и при решении практических и теоретических проблем в военном образовании $[5,6]$.

Таким образом, необходимо констатировать, что на основе развития представлений о структуре, видах и компонентах профессиональной деятельности специалистов, возможно формирование модели военно-профессиональной подготовки будущего военного инженеpa ACY.

Рассмотренные выше особенности моделирования профессиональной дея-тельности позволяют построить модель профессиональной подготовки, которую, в соответствии с предложенной В.П. Беспалько классификацией педагогических систем, можно представить в виде замкнутого управляемого процесса (рис.6). 


\section{ЛИТЕРАТУРА}

1. Менчинская Н.А. Проблемы учения и умственного развития школьника. М.: Педагогика. 1989.218 с.

2. Усова А.В. Психолого-дидактические условия формирования у учащихся научных понятий. Челябинск: ЧГПИ, 1988. 88 с.

3. Гальперин П.Я. Методы обучения и умственное развитие ребенка. М.: Изд-во Моск.ун-та, 1985. 45 с.

4. Талызина Н.Ф. Теоретические проблемы программированного обучения. Изд-во МГУ, 1969. 268 с.

5. Полякова В.А., Козлов 0.А. Модель подготовки педагогических и управ-ленческих кадров в области использования средств информационных и коммуникационных технологий для системы высшего профессионального образования // Педагогическая информатика. 2015. № 2. С. 44-57.

6. Козлов 0.А. «0 возможности применения методов математического моделирования и информационных технологий в оценке деятельности учреждений профессионального образования» //В сборнике: Инновации и традиции: современные вызовы развития педагогического образования Материалы Международной научно-практической конференции. Печатается по решению Ученого совета Института социально-гуманитарных технологий, протокол № 9 от 19 мая 2016 года. 2016. С. 504-511.

(c) Емельянов Андрей Дмитриевич (emelyanovad@bk.ru).

Журнал «Современная наука: актуальные проблемы теории и практики»

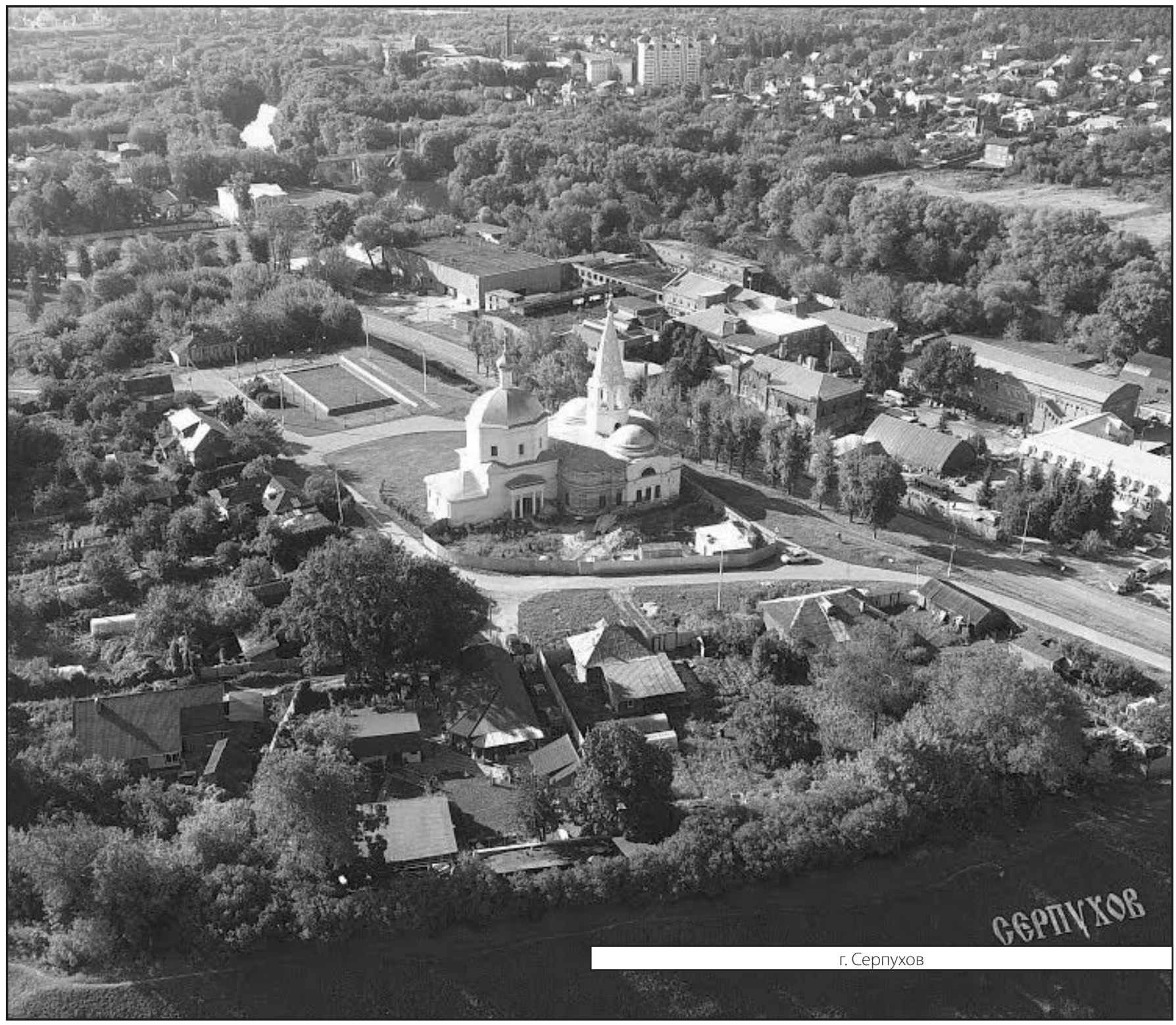

